\title{
Implementation of MCA Method for Identification of Factors for Conceptual Cost Estimation of Residential Buildings.
}

\author{
Michał Juszczyk, Agnieszka Leśniak, Krzysztof Zima \\ Cracow University of Technology \\ Faculty of Civil Engineering, Section of Building Technology and Organization \\ e-mail: mjuszczyk@izwbit.pk.edu.pl, alesniak@izwbit.pk.edu.pl,kzima@izwbit.pk.edu.pl
}

\begin{abstract}
Conceptual cost estimation is important for construction projects. Either underestimation or overestimation of building raising cost may lead to failure of a project. In the paper authors present application of a multicriteria comparative analysis (MCA) in order to select factors influencing residential building raising cost. The aim of the analysis is to indicate key factors useful in conceptual cost estimation in the early design stage. Key factors are being investigated on basis of the elementary information about the function, form and structure of the building, and primary assumptions of technological and organizational solutions applied in construction process. The mentioned factors are considered as variables of the model which aim is to make possible conceptual cost estimation fast and with satisfying accuracy. The whole analysis included three steps: preliminary research, choice of a set of potential variables and reduction of this set to select the final set of variables. Multicriteria comparative analysis is applied in problem solution. Performed analysis allowed to select group of factors, defined well enough at the conceptual stage of the design process, to be used as a describing variables of the model.
\end{abstract}

Key words: residential building cost, conceptual cost estimation, cost factors, multicriteria comparative analysis

\section{Introduction}

This paper aims to present the application of multicriteria comparative analysis to identify the factors which allow estimating, in the early design stage, the costs of construction of a residential building or a residential building with a separated commercial part. Cost estimation of a building structure is based on the information about the structure. The source of information is a technical documentation developed at the following stages of the project process from pre-design analyses, through conceptual designs, a building design, and finally to working drawings. Special attention should be paid to the cost estimates in the early design stage, carried out on the stage of development of the conceptual design or in the initial stage of the building design. Information on the civil structure is still imprecise, incomplete - only the function and general assumptions regarding the form and design solutions are known. Despite the qualitative nature of such estimates 
their importance cannot be overestimated. "Decisions made during design process - especially in its early stage - are of key importance to the shape and nature of the project. It is also then, when the strongest impact on cost shaping is possible too. Errors committed at that time may lead to a failure of the entire project. "[5]

\section{Aims and methodology of research}

The analysis presented in this paper, was to identify the factors - the carriers of information about the building - which could ultimately be used in modeling the implementation costs of the buildings with application of artificial neural networks.

It was assumed that such estimates will be based on a few or more parameters of the building, known in the early design stage. The general form of the model is represented by the following equation (1):

$$
Y=F\left(X_{j}, \varepsilon\right)
$$

where:

- $Y$ - described variable (model baseline) - the cost of the construction of a building,

- $X_{j}-$ describing variables (factors - input data of the model),

- $F$ - correlation function binding the describing variables (input data) and the described (baseline) variable of the model,

$-\varepsilon-$ model error.

It was assumed that the described variable $\mathrm{Y}$ will be the costs of a residential building or residential and commercial building in respect of:

- the cost of site preparation works;

- the cost of construction works, including:

- cost of a zero level;

- cost of a building shell;

- cost of interior finish;

- cost of exterior finish;

- the cost of installation works and facilities of the primary equipment;

(The modeling excludes the cost of land improvement and landscaping.)

The study of identification of describing variables was conducted in the following stages:

- analysis of the literature (desk research);

- analysis of project documentation, cost estimates and settlements of cost of the buildings (desk research);

- - consultations interviews on the proposed describing variables with experts in cost estimate calculation, cost estimate of the construction of residential buildings and cost settlements of the construction projects;

- selecting an initial set of variables describing the model;

- multicriteria comparative analysis - reducing the initial set of describing variables;

- selecting a final set of variables describing the model. 
To analyze and reduce the initial set of describing variables the components of multicriteria comparative analysis (MCA) were employed. (Theoretical background and methodology of the analysis are presented in the literature [8]). MCA method comprises of several steps - the first step is to select factors that may have influence on a phenomenon that being investigated. When the factors are selected a matrix of arcs is being drawn. The dimensions of the matrix are $n+1 \times n+1$ where $n$ is equal to the number of selected factors. In the course of building the matrix of arcs, the analysis of all pairs of factors is performed (if $j$ and $k$ stand for the analisys is performed if $j \neq k(j=1, \ldots, n$; $k=1, \ldots, \mathrm{n})$. If the information brought by the factors overlaps at least partially, the correlation in the analyzed pair of variables is investigated. If the $j$ variable contained the information about the $k$ variable, the elements of the matrix of arcs were assigned $g(j, k)=1$ and $g(k, j)=0$, respectively. If the information carried by the variables $K_{j}$ and $K_{k}$ were independent, then $g(j, k)=g(k, j)=0$. For $j=$ $k$ elements of the matrix of arcs are equal $0-g(j, k)=g(k, j)=0$. To ensure the consistency of the graph - which is built later in the analysis - also an additional global variable with $n+1, n+1$ indexes is introduced. The matrix elements are assigned the values of $g(n+1, k)=1$ whereas $g(j, n+1)=0$ for $(j=1, \ldots, 33 ; k=1, \ldots, 33)$ and $g(n+1, n+1)=0$.

In the next step on the basis of the matrix of arcs a layer-structured graph is built. The vertices of the graph correspond to variables with $j$ indexes and $n+1$ index. The oriented arcs connect the vertices in the order of $j \rightarrow k$ for $g(j, k)=1$ and $\mathrm{n}+1 \rightarrow k$ for $g(\mathrm{n}+1, k)=1$. The vertices were assigned to the corresponding layers, determining their row. To this end, the first step was to calculate the number of arcs entering the $k$-vertex (2):

$$
b_{k}^{0}=\sum_{j=1}^{n+1=34} g_{j k}
$$

For vertices $k$, for which $b_{k}{ }^{0}=0$ the vertex row is equal to 0 . In the following steps the next rows of vertices were calculated from 1 to $r(3)$ :

$$
b_{k}^{l}=\left\{\begin{array}{c}
0^{*} \text { when } b_{k}^{l-1}=0 \vee b_{k}^{l-1}=0^{*} \\
b_{k}^{l-1}-\sum_{j=Z_{l-1}} g(j, k) \text { when } b_{k}^{l-1} \neq 0
\end{array} \quad k=1, \ldots, n+1 ; l=1, \ldots, r\right.
$$

where:

$Z_{l-1}-$ set of vertices for which $b_{k}^{l}=0$.

The vertices for which $b_{k}{ }^{l}=0$ are assigned an $l$-row. The calculation process is completed at the time of assigning the row to all vertices. The row determines the vertex assignment to the $l$-layer of the graph. Factors from one chosen layer of the graph should be considered, as the representative set of factors for further modeling.

\section{Initial set of potential factors for conceptual estimation of residential buildings costs}

The prospected factors - variables describing the model - were assumed to represent the parameters of the designed residential or residential-commercial building related to its form, function and structure. Information about these parameters should be available on the stage of the conceptual design or in the early stage of the building design. 
Analysis of the literature [1], [2], [3], [4], [6], [7], [9] and interviews and consultations held during the studies with the group of experts led to the selection of the initial set of 33 potential variables describing the model. The interview method was used in course of the research. Interlocutors (the experts mentioned before - professionals with practical knowledge in the field of cost estimation) were asked to make a list of factors defined well enough at the conceptual stage of the design process, to be used for conceptual cost estimation. The most frequently appearing factors were ordered into five groups. Ordered list of factors were confronted with the literature during the phase of desk research and then presented to the experts once again. Finally approved list included 33 factors.

For purposes of further analysis the potential variables are named as $K_{j}$ where $j=1, \ldots, 33$. This set, organized into five subsets, is presented in the Table 1.

Due to striving for a simple form of the model, and possible application of the model in practice, the analysis and reduction of the initial set of variables was performed. The number of variables describing the model, acceptable from the point of view of practical application of the model, was identified during the interviews with experts. As a result of the consultations carried out with experts it was stated that the number of variables describing the model should not exceed 15.

Tab. 1: The initial set of variables describing the model.

\begin{tabular}{|c|c|}
\hline 1. Potential Variables characterizing the size of the building: & Variable symbol \\
\hline 1.1. total area of the building, & $K_{1}$ \\
\hline 1.2. footprint, & $K_{2}$ \\
\hline 1.3. cubature, & $K_{3}$ \\
\hline 1.4. inner surface area of the building, & $K_{4}$ \\
\hline 1.5. area of building structure, & $K_{5}$ \\
\hline 1.6. building storey height, & $K_{6}$ \\
\hline 1.7. number of storeys, & $K_{7}$ \\
\hline 1.8. number of underground storeys, & $K_{8}$ \\
\hline 1.9. number of above ground storeys. & $K_{9}$ \\
\hline 2. Potential variables characterizing the structure of the building: & Variable symbol \\
\hline 2.1. strengthening and stabilization of the subsoil, & $K_{10}$ \\
\hline 2.2. type of foundation & $K_{11}$ \\
\hline 2.3. structure of the building, & $K_{12}$ \\
\hline 2.4. roof structure, & $K_{13}$ \\
\hline 2.5. type of key material solutions, & $K_{14}$ \\
\hline 2.6. number of structural segments of the building, & $K_{15}$ \\
\hline 2.7. number of elevator shafts in the building. & $K_{16}$ \\
\hline 3. Potential variables characterizing the construction site: & Variable symbol \\
\hline 3.1. availability of the building site, & $K_{17}$ \\
\hline 3.2. number of tower cranes on the construction site, & $K_{18}$ \\
\hline 3.3. conditions of construction site development, & $K_{19}$ \\
\hline 3.4. ground conditions. & $K_{20}$ \\
\hline 4. Potential variables characterizing the building functions as well as equipment and systems: & Variable symbol \\
\hline 4.1. residential function - usable area of dwellings, & $K_{21}$ \\
\hline 4.2. commercial functions - usable area of commercial premises, & $K_{22}$ \\
\hline
\end{tabular}




\begin{tabular}{|l|c|}
\hline 4.3. underground garages in the building - usable area of underground garages, & $K_{23}$ \\
\hline 4.4. building equipment, sanitary systems, & $K_{24}$ \\
\hline 4.5. building equipment, central heating system and appliances, & $K_{25}$ \\
\hline 4.6. building equipment, electrical wiring system, & $K_{26}$ \\
\hline 4.7. building equipment, mechanical ventilation systems, & $K_{27}$ \\
\hline 4.8. building equipment, telecommunication systems, & $K_{28}$ \\
\hline 4.9. building equipment, passenger lifts, & $K_{29}$ \\
\hline 4.10. number of staircases. & $K_{30}$ \\
\hline 5. Potential variables characterizing the form and standard of the building: & Variable symbol \\
\hline 5.1. shape of the horizontal projection of the building, & $K_{31}$ \\
\hline 5.2. body of the building, & $K_{32}$ \\
\hline 5.3. finishing standard of dwellings & $K_{33}$ \\
\hline
\end{tabular}

\section{Reduction of the set of potential factors for conceptual estimation of residential buildings costs}

The following objectives of the analysis were formulated:

- qualification of the describing variables for the model by their isolation from the set presented in Table 1,

- proposition of the simplest model possible,

- reduction of the data redundancy,

- prevention of the phenomenon of the "curse of dimensionality" because of the foresight of neural modeling.

The variables belonging to the initial set of describing variables were analyzed in terms of:

- introduced information,

- representativeness (information carrying capacity),

- mutual relationships between variables,

- availability of information on the value of the given variable on the stage of the conceptual design or the early stage of the building design.

In the course of the analysis a matrix of $G$ arcs was built with the dimensions of $n+1=34 \times n+1=34$ where $n=33$ is the number of $K_{j}$. Building the $\mathrm{G}$ matrix, the analysis of all pairs of variables $K_{j}, K_{k}$ for $j \neq k(j=1, \ldots, 33 ; k=1, \ldots, 33)$ was performed in terms of information, which the variables contribute to the described variable. If the $K_{j}$ variable contained the information about the $K_{k}$ variable, the elements of the $\mathrm{G}$ matrix were assigned $g(j, k)=1$ and $g(k, j)=0$, respectively. If the information carried by the variables $K_{j}$ and $K_{k}$ were independent, then $g(j, k)=g(k, j)=0$.

To ensure the consistency of the graph also an additional global variable $K_{34}$ was introduced. The matrix elements were assigned the values of $g(34, k)=1$ whereas $g(j, 34)=0$ for $(j=1, \ldots, 33$; $k=1, \ldots, 33)$. For $j=k g(j, k)=0$, and $g(34,34)=0$, as well. The matrix $G$ is shown in the Fig.1. 


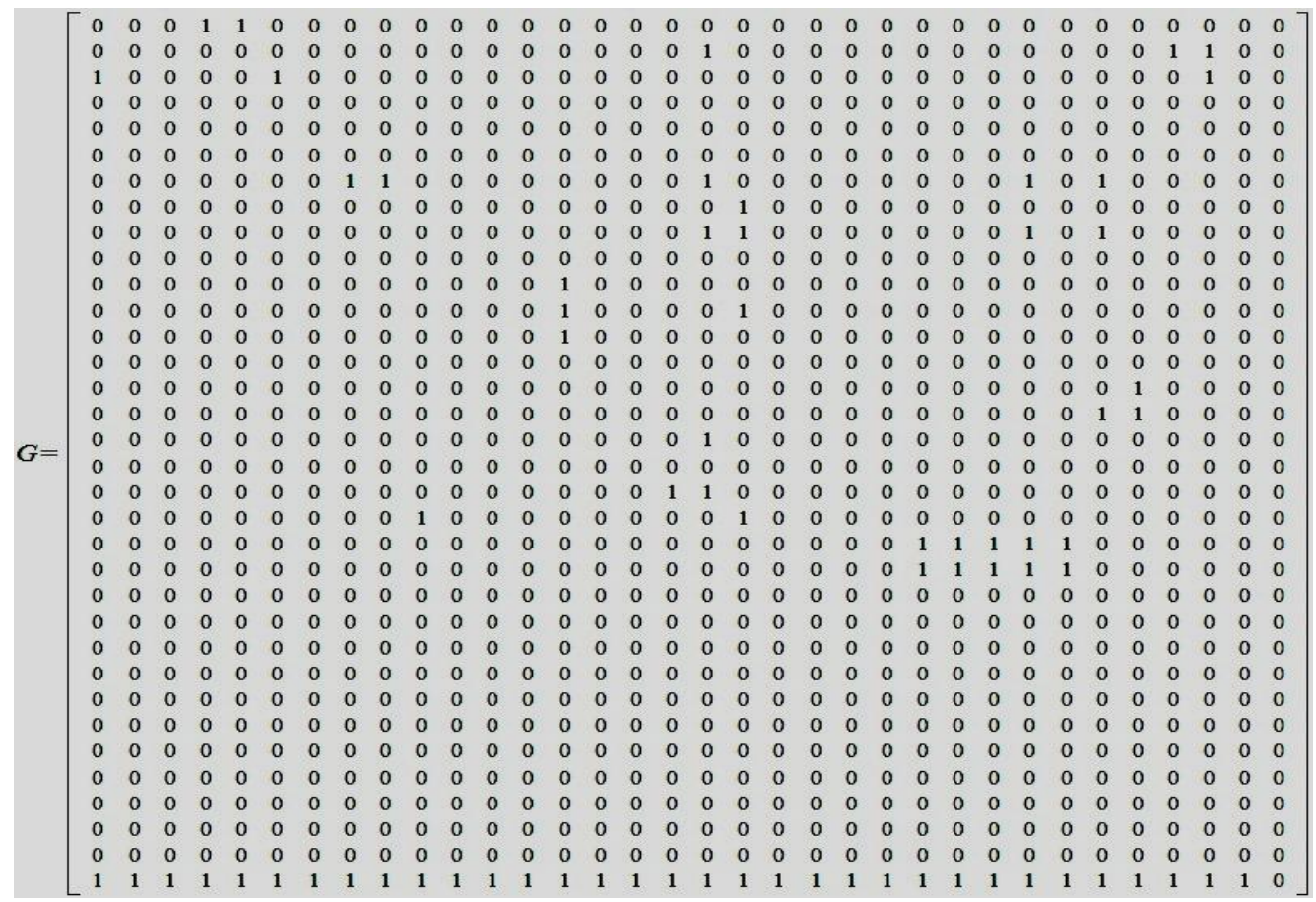

Figure 1: Matrix $G$

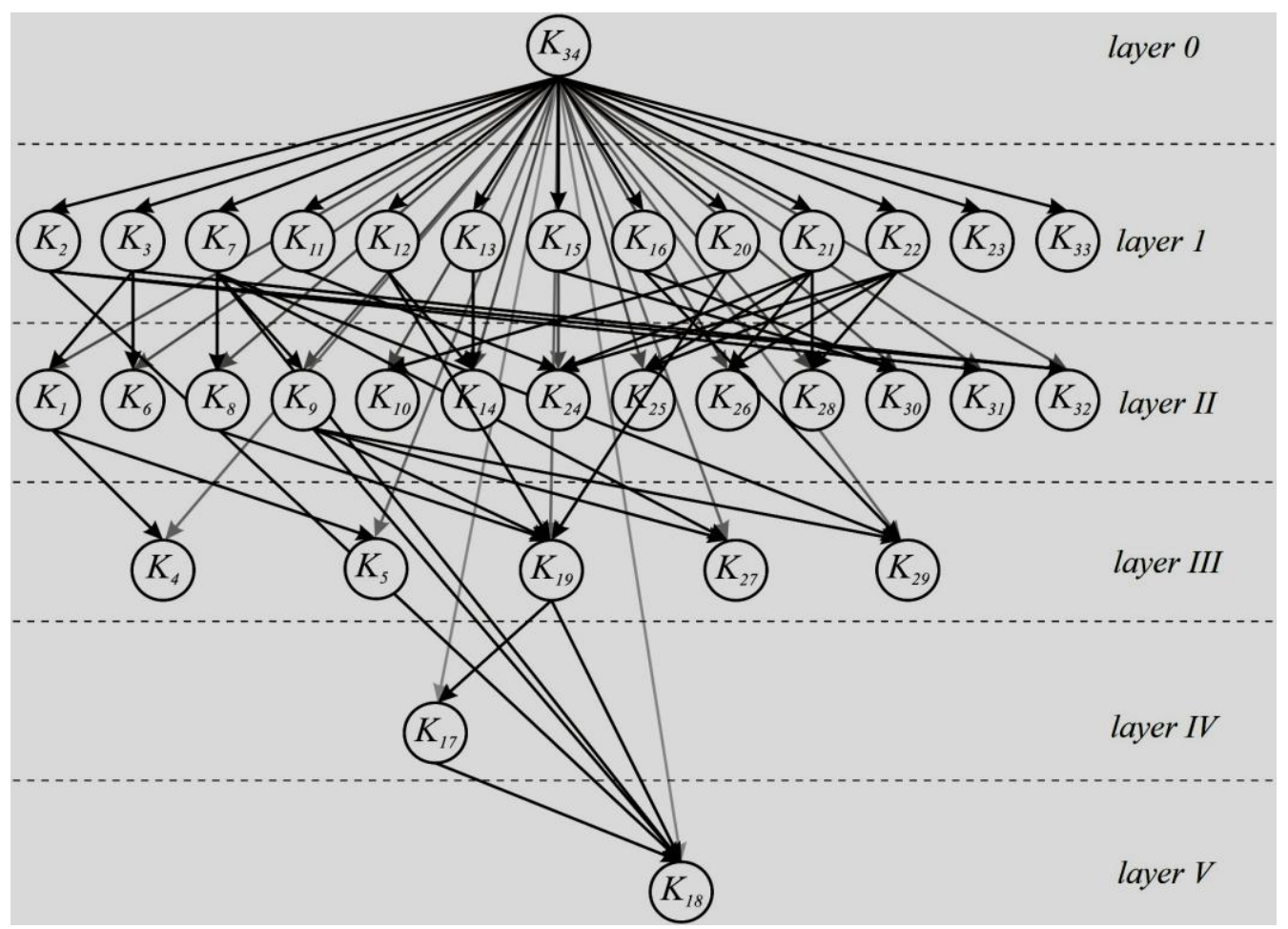

Figure 2: Layer-structured graph. 
In the course of calculations, the rows of all graph vertices were determined and the $K_{j}$ variables were assigned to individual layers (according to formula (2) and (3)). Layer-structured graph is shown in Fig. 2. The variables from the first layer: $K_{2}, K_{3}, K_{7}, K_{11}, K_{12}, K_{13}, K_{15}, K_{16}, K_{20}, K_{21}, K_{22}$, $K_{23}, K_{33}$ were qualified for the final set of variables (according to the rule for selecting the variables from one layer of the graph [8]). Other variables were rejected as duplicating the information brought to the model. In order to verify the results of the analysis the final set of variables of the model was consulted with experts with interview method. The final set of variables has been accepted by experts in both the number of variables and information brought to the model.

\section{Final set of factors for conceptual estimation of residential buildings costs}

The analyses allowed to select the ultimate set of 13 describing variables of the model. For further steps the describing variables of the model were renumbered as follows:

- footprint: $K_{2} \rightarrow X_{1}$, cubature: $K_{3} \rightarrow X_{2}$, number of building storeys: $K_{7} \rightarrow X_{3}$

- type of foundation: $K_{11} \rightarrow X_{4}$, building structure: $K_{12} \rightarrow X_{5}$, roof structure: $K_{13} \rightarrow X_{6}$, number of structural segments of the building: $K_{15} \rightarrow X_{7}$, number of elevator shafts: $K_{16} \rightarrow$ $X_{8}$

- ground conditions: $K_{20} \rightarrow X_{9}$

- usable area of dwellings: $K_{21} \rightarrow X_{10}$, usable area of commercial premises: $K_{22} \rightarrow X_{11}$, usable area of underground garages: $K_{23} \rightarrow X_{12}$

- building finishing standard: $K_{33} \rightarrow X_{13}$

The role of the variables $X_{1}, X_{2}, X_{3}$ is to bring the information about size-related parameters of the buildings to the model. The influence of the building size on the cost of its implementation is obvious - the bigger the building the higher the direct costs (building materials, labor and equipment operation), and consequently the higher the costs of overhead on direct costs. The values of the variables are easy to determine at an early stage of design, even based on the basic concept sketches.

The variable $X_{l}$ represented the information about the size of the building in the model as an area of the building projection - footprint in $\mathrm{m}^{2}$. The use of this parameter in estimating the implementation cost of the buildings was proposed in the methods presented in the literature [1].

The variable $X_{2}$ brought the information about the spatial measure of the building size to the model. The volume of the building (cubature), expressed in $\mathrm{m}^{3}$ is used in the index-based cost estimates [1], [4].

The variable $X_{3}$ expressed as a number of storeys of the building brought a number of important information to the model. The number of storeys has a multifaceted impact on the cost of the building implementation [1], [4], [6], [9]. As the number of storeys increases, and therefore the height of the building, the requirements for structural solutions increase too, arising from the need to transfer the weight of the building and wind loads through the structure and to provide adequate stiffness of the building. Also the requirements for fire protection and building equipment increase. It becomes necessary to ensure a smooth vertical transportation of building materials, which is prolonged with the increase in building height. 
The structure forms an important part of the total costs of raising a residential building, which is emphasized by the authors analyzing these costs [1], [3], [4]. The construction of the building structure is time-consuming, labor-intensive and material-consuming. The cost of raising the structure depends on the type, size and complexity of the building. The task of the variables $X_{4}, X_{5}$, $X_{6}, X_{7}, X_{8}$ is a representation of the information about the types of structural solutions applied at the level of accuracy adequate for estimates made in the early design stage.

The variable $X_{4}$ brings the information on the method of a building foundation, the type of foundation, to the model. The cost of the foundation of the building depends on the applied design solution of the building foundations. The following factors affecting the cost of foundation are cited in the literature [1], [4]:

- size and structure of the building (the load to be transferred to the subsoil),

- bearing capacity and stratification of the subsoil,

- type and distance of neighboring buildings or other civil structures (considering in particular the method and the depth of their foundation),

- type of foundation.

The variable $X_{4}$ will take one of the three values corresponding to the variants of foundation, namely: continuous footing, foundation slab or intermediary foundation.

The variable $X_{5}$ provides the information on the construction and technological solutions of a multi-family residential building or a residential-commercial building in terms of the nature of the supporting structure, which is constituted by the floors and structural walls (or columns). The analyze of the structure costs presented in the literature [9] indicate a significant share of the cost of structural walls and floors (ca. 40\%) in the cost of the total building implementation. The values of the variable $X_{5}$ will correspond to the information specifying the type of the structure: the traditional, core, core bracing walls, reinforced concrete walls or reinforced concrete monolithic.

The variable $X_{6}$ represents the information about the applied design solution for the building roof in terms of the structure and slope. (Notes on the roof costs, resulting from its design and the number of roof surfaces can be found in the literature [1].) The values of the variable $X_{6}$ will correspond to one of two possibilities: application of a flat roof or wooden structure in the building.

The variable $X_{7}$ brings the information on the division of the whole building into independent structural segments. The structural segment was assumed as a part of the building of independent structural system, constituting a uniform entirety in terms of statics, separated from the rest of the building parts with expansion joints. Indirectly, this variable also tells of the size of the building - a large number of structural segments mean the considerable dimensions of the building in plan view. The variable also brings some information about the functional layout of the building. In the residential buildings the division into segments usually corresponds to the separation of the building sections with independent circulation systems.

The variable $X_{8}$ was qualified for the group of variables which characterize the structure of the building because of the vital role of elevator shafts. Reinforced concrete, monolithic elevator shafts (including the staircase core) are treated as the elements of the structure, which ensure spatial rigidity. This role is particularly important for buildings of traditional structure with masonry bearing walls. The variable also brings important information about the building equipment in the 
form of elevators. The values of the variable $X_{8}$ determine the number of elevator shafts in the building.

The variable $X_{9}$ introduced the information about ground conditions to the model. The ground conditions determine the layout and type of ground layers, groundwater level and the possibility of adverse geological phenomena occurrence - it has a crucial influence on the foundation of the building. This factor, as important for the cost of the buildings, is indicated in the literature [1]. Ground conditions affect the solutions of the foundation design of the building, and also determine when to replace, reinforce or stabilize the subsoil on which the building is seated. Adverse groundwater level may cause difficulties in earthworks, the need for special protection against excavation landslides, trench drainage, heavy water insulation of the building and perimeter drainage. The values of the variable $X_{9}$ correspond to one of three possibilities corresponding to the types of ground conditions: simple, complex and complicated.

The task of the variables $X_{10}, X_{11}, X_{12}$ is to characterize the functions of the building. These variables introduce the information on the three different functions implemented in the building, and also provide a measure of the building size.

The variable $X_{10}$ will represent the information about the surface area (expressed in $\mathrm{m}^{2}$ ) designed to meet the demands of the residential function. The usable area of dwellings in the designed building is one of the most important information for the Client. The most common behavior is to seek to maximize the share of usable area of dwellings in the total usable area of a building. The following definition was assumed - a usable area of dwellings is the sum of surface areas being directly a part of the dwellings subdivided in the building. (The usable area of a single dwelling is separated with the walls that insulate a given dwelling from other units and other parts of the building).

The variable $X_{11}$ provides information about the usable area of commercial premises (expressed in $\mathrm{m}^{2}$ ). A definition analogous to that of a usable area of dwellings was adopted. The usable area of commercial premises in the building is the sum of the surfaces being directly a part of the commercial premises separated in the building. The usable area of a single commercial unit is separated with the walls that insulate a given commercial unit from other commercial premises and other parts of the building.

The variable $X_{12}$ will bring the information about the surface area (expressed in $\mathrm{m}^{2}$ ) intended for the function of underground garages in the building. To clearly determine the usable area of underground garages the following definition was adopted: the usable area of underground garages in the building is the sum of the surface areas of the premises being directly a part of the underground garages in the building. (The surfaces intended for implementation of these functions were assumed in the clear of the walls limiting the underground garage premises.).

The variable $X_{13}$ is the carrier of information about the standard of the dwelling finish in the building. The importance of the scope of the finishing works for the cost of the building, was emphasized by the experts during interviews conducted in this study. The variable values will be expressed by the range of finishing work to be carried out in dwellings. The developer's standard is defined as a condition of the unit prepared to individual finish made by a purchaser of a dwelling or a purchaser (or a lessee) of a commercial premises. The turn-key finish standard is defined as a condition of the unit, in which the full range of finishing works has been performed. 


\section{Conclusion}

The performed analysis, which uses a multicriteria comparative analysis element, allowed selecting a set of factors - the describing variables of the model, whose purpose is to allow estimation of the cost of the residential building at an early stage of design. The proposed set of variables includes the building parameters related to its size, structure, function and standard of finish. Some part of the factors chosen in the course of the analysis can be expressed as numerical values. Some factors take the descriptive values. For the application of the factors, which are characterized by the descriptive values, the system for their conversion into the numerical values should be developed. The factors selected during the analysis will provide the input parameters for artificial neural networks that will be proposed for implementation of the regression function in a non-explicit way (functional relation $F$ from the formula number (1)). Set of factors selected in the course of the analysis will be examined during next phase of research. Further research will include neural modeling - especially: learning and testing artificial neural network models.

\section{References}

[1] ASHWORTH A.(2004). Cost studies of buildings. Pearson Prentice Hall, Harlow-Oxford.

[2] JAGGER D., ROSS A., SMITH J., LOVE P.(2002). Building Design Cost Management, WileyBlackwell.

[3] JAWORSKI K.M. (1999) Metodologia projektowania organizacji budowy. Wydawnictwo Naukowe PWN, Warszawa.

[4] KIRKHAM R. (2007). Ferry and Brandon's Cost Planning of Buildings. Blackwell Publishing, Singapore.

[5] KOWALCZYK Z., ZABIELSKI J. (2005). Kosztorysowanie $i$ normowanie $w$ budownictwie. Wydawnictwa Szkolne i Pedagogiczne, Warszawa.

[6] PASQUIRE C.L., SWAFFIELD L.M. (1999). Examination of relationships between building form and function, and the cost of mechanical and electrical services. Construction Management and Economics, Volume 17, Issue 4, 483-492

[7] POTTS K. (2008). Construction cost management. Learning from case studies. Taylor \& Francis, London, New York.

[8] SZWABOWSKI J., DESZCZ J. (2001). Metody wielokryterialnej analizy porównawczej. Podstawy teoretyczne i przyklady zastosowań w budownictwie. Wydawnictwo Politechniki Śląskiej, Gliwice.

[9] UHMA C. (1998). Ekonomika budownictwa. Wydawnictwa Szkolne i Pedagogiczne, Warszawa. 